\title{
Sociological Analysis of the Nation's Identity, the Levels of Feeling the National Identity in Uzbekistan
}

\author{
Kadirova Halima Buvabaevna, Akhmedova Feruza Medetovna
}

\begin{abstract}
This article deals with issues related to sociological analysis of the distinctive lifestyle, customs and traditions of the Uzbek and Karakalpak peoples in Uzbekistan. Determining the attitude of the respondents to the history, culture, spiritual heritage of the people, as well as the spirituality of the nation is presented by the results of research on its history, customs, traditions and life values.
\end{abstract}

Keywords: lifestyle, customs, culture, spirituality, identity, traditions, values, self-consciousness, historical memory, mentality, historical monuments, spiritual heritage, historical monuments, national consciousness, thought.

\section{INTRODUCTION}

Nothing in great history goes without a trace. It is stored in the blood of nations, in its historical memory and manifested in its practical work. Therefore, it is powerful. Preservation and study of historical heritage is one of the most important priorities of state policy [1, p.144].

After all, national values, self-awareness, historical memory play an important role in the spiritual development of our people. Indeed, after the independence of our country, all the opportunities have been created to fully restore our national culture and history. Positive changes have taken place in the life of our people. In this regard, Shavkat Mirziyoyev underlines that based on our achievements over the years of independence, we are confidently moving forward from national revival to national development.

It should be noted that, no matter how high or difficult the goals are, we have every opportunity to reach them. The legacy of our ancestors, the scientific and creative potential of our people, and their entrepreneurial qualities will provide us with an invaluable source of energy .

We need to develop a national idea that will serve as a source of strength for us to carry out our ambitious tasks. In particular, the understanding of national identity, the language, customs, traditions, values, territorial unity, and mentality of the nation is an independent mark of the nation. National self-awareness is defined by the independence of the nation - the need to protect the common interests of the nation, the needs and the need to achieve national development and strengthen its place in the world community.

After all, national identity combines all the features and features of nationality. It is a natural process for each individual to seek national identity. The nation, the ethnicity of the nation to which it belongs, is an expression of its efforts to preserve, further develop or restore the symbols [2, p.32].

The distinctive way of life and customs of the Uzbek and Karakalpak peoples has been developed and polished for centuries, which is still distinguished from other cultures by its unique features.

The cultural roots of both the Uzbek and Karakalpak peoples are distinct with their deep and rich history. These lands also included blends of cultural traditions of different nations. Certainly, the spirituality of each nation cannot be imagined without its history, traditions, customs and traditions of its own identity. Certainly, spiritual heritage, cultural treasures and ancient historical monuments are the most important factors in this regard. While examining why the concept of culture is expressed through the expression of cultural identity today, we understand its spiritual imperative, its national imperatives, the national spirit when it defines the cultural development of societies and states [3, p. 154].

In this sense, national consciousness is considered as a factor of the nation's development, and national selfawareness must be formed as a spiritual and ideological force that protects and promotes national interests. The basis of national self-consciousness is national pride.

National pride is fully formed in a nation that understands itself. In particular, the President said that "we should pay special attention to the invaluable legacy of our great scholars and writers, saints, the priceless heritage of our great sages and figures, to instill the courage of our invincible commanders and leaders in their minds."

The development of national consciousness is seen as the development of language, values, customs and traditions of a particular nation from simple to complex. The process of formation of the national consciousness will increase the level of national self-consciousness of each nation. National self-awareness is also the real power as a uniting factor. And the nation's self-awareness creates national pride. In turn, national pride provides spiritual and spiritual understanding of national identity. National pride is, above all, a reflection of the process of national self-consciousness becoming a sense of national pride. National self-awareness is reflected in the understanding of each person's ethnicity, his or her role in the development of the world.

Revised Manuscript Received on 14, October 2019.

Kadirova Halima Buvabaevna, Senior lecturer at Tashkent State Pedagogical University named after Nizami, Uzbekistan.

Akhmedova Feruza Medetovna, National University of Uzbekistan named after Mirzo Ulugbek, Uzbekistan.(Email: farihon72@mail.ru). 


\section{SOCIOLOGICAL ANALYSIS OF THE NATION'S IDENTITY, THE LEVELS OF FEELING THE NATIONAL IDENTITY IN UZBEKISTAN}

Human history testifies that identity, national identity is not always fully felt by all strata of citizens. It is understood first of all by the progressive groups and societies that this reality is important. Therefore, from the very first days of independence the restoration of the invaluable spiritual and cultural heritage created by our ancestors for many centuries has reached the level of state policy. National identity, national self-consciousness is connected with the ancient behavior of our ancestors, their thoughts, dreams and aspirations, respect for the Motherland, traditions, and all spheres of life with its practical importance. National identity and national self-awareness are such factors that it is possible to protect the nation from any harmful effects only by raising it to the highest level of development. This is because it is a high moral value that perpetuates the national interests, pride, pride, honor, honor, responsibility and responsibility as a factor in understanding the national identity and traditions. Consequently, it is necessary to study, develop, respect, and develop the material and spiritual culture, history, language, national values and traditions that have been created for thousands of years for the well-being and prosperity of peoples. "Respect for cultural heritage is, first and foremost, an endless respect and kindness for the people, the nation, and the past, which is its creator, protector and developer. A person who does not deeply know and respect the past cultural heritage of Uzbekistan does not know and cannot know its roots, the way its ancestors have passed. Such a person will not have such a future. [4, p.61].

Every person, along with his or her ethnicity, lives, cherishes, and loves another country, that is, his homeland.

"To be more attentive, to preserve and strengthen the solidarity of our multinational people, which is our main asset and which we are proud of, is a sacred duty of anyone who sees Uzbekistan as their motherland" [5, p.146].

In determining the level of national identity it is important to determine the attitude of the respondents to the history, culture, and spiritual heritage of their people. Because, the development of national identity is of great importance for all stages of political, social, spiritual and moral development of the country and its role will continue to grow.

That is why the Republican Center for the Study of Public Opinion "Ijtimoiy Fikr" ("Social idea") regularly conducts research on the self-awareness of the people of Uzbekistan in the sense of national identity. The purpose of the research is the concept of further deepening of democratic reforms and formation of civil society in the country, the dynamics of the process of forming national identity of the population, its structure and content in accordance with the objectives of the President of the Republic of Uzbekistan Sh.Mirziyoyev "On Measures for Further Improvement of Interethnic Relations and Friendship with Foreign Countries" dated May 22, 2017 and "On the Strategy of Action for the Further Development of the Republic of Uzbekistan" to identify the status and development trends of interethnic relations in the country, the dynamics of their changes over the years of independence. Today, the level of development of national self-consciousness is shown by the results of surveys conducted in Tashkent, Karakalpakstan and all regions of Uzbekistan on the topic "Self-awareness of Uzbeks" and "Emotional part of civil self-consciousness" in 1999-2018.

In these studies, the parameters of the study of national self-consciousness explored participants' perceptions of the nation, its ethnicity, the manifestation of national feelings, the level of knowledge of the history, culture and spiritual heritage of the people, the history of Uzbekistan, the history and culture of the country.

Respondents' answers to questions about the history of the population are as follows. Of the respondents (43.7\%) answered that they know enough about the history and culture of the country (44.1\%), but not enough (12.2\%). ) replied that they do not know (2004) [6, No. 2].

The respondents from Fergana (49.4\%) and Samarkand (47.9\%) are the most knowledgeable about the region's history. The respondents in Bukhara region (19.0\%) admit that they do not know the history of the country.

The majority of Karakalpaks $(60 \%)$ believe that they know enough about the history of the country, with almost half of the Slavs reporting that they know the history of the country in general, but do not know enough (49.5\%). Kazakhs (30.2\%) and the smallest Kyrgyz (8.3\%) were the highest among those who did not know. From the answers to the question posed it can be argued that respondents know only partially the history of the country.

Karakalpaks (39.2\%) are well aware of Uzbekistan's history and culture by region. $28.2 \%$ of the respondents are from Tashkent, with the least knowledge.

As in previous responses to the questions, Karakalpaks $(49.3 \%)$ and Tajiks $(45.5 \%)$ showed a good knowledge of the country's history. Kyrgyz (66.7\%), Slavic (61.6\%), ethnic groups $(60.9 \%)$, and more than half of Uzbeks $(57.9 \%)$ as a sociological fact know little about the history of Uzbekistan. One in three Kazakhs (3.7\%), Kyrgyz (16.7\%), Slavs, and Tajiks (15.2\%) do not know the history of their country.

The data presented show that, although these sociological surveys have been conducted for several years, the underlying cause and effect of national development of national self-consciousness is far behind today's needs.

First of all, it is due to the "tendency" of the former Soviet government to engage the changes that are firmly established in the national consciousness.

Secondly, under the strong information pressure of the national consciousness is undergoing development. Whoever dominates this information system, its products are becoming a source of spiritual growth for others. The most important thing is that this information system can be used effectively in the promotion of the country in a way that is higher than any other factor. When adding the agenda to achieve the objective.

Thirdly, it is also important to focus on the development of national awareness, effective use of the aforementioned functions in accordance with the needs of national consciousness. [7, p.137]. It is well known that renewing public consciousness is not a year or two, but a continuous process.

Published By:

Blue Eyes Intelligence Engineering 
After all, self-awareness is a product of national consciousness, and is a unifying force that unites emotional and rational ideas that reveal the level of national consciousness. have. More than half of Uzbeks view citizenship not as a passport, but as a set of people with a specific person $(63.6 \%)$, human history $(62.9 \%)$, country and state $(62.7 \%)$, mother tongue, history, and culture. (43.7\%) understand.

Comparative analysis of studies shows that since 2004 the number of people belonging to a particular person has steadily increased (from $45.7 \%$ in 2004 to $63.6 \%$ in 2015) and their understanding of historical roots (41.7\% in 2004). from $62.9 \%$ in 2015) .

The sociological survey revealed the attitude of the people of Uzbekistan to the concept of "nation" as follows. Every fourth respondent $(22.7 \%)$ expressed his view of the nation on the basis of his or her ethnicity, suggesting the importance of this feature of the population of Uzbekistan.

Rural populations often emphasize the historical roots of urban populations (67\% and $58.1 \%$, respectively), singlecommunity communities (68.4\% and $57.2 \%$, respectively), and the individual's ethnicity (25.7\% and 16 , respectively). $7 \%$ ). Mostly rural people show their own understanding of the nation as a set of people with the same language, history, and culture $(51.4 \%$ and $40.8 .1 \%)$ [8, p.98].

Table 1

Distribution of respondents' response to the question "How do you feel about being a citizen of Uzbekistan?"

\begin{tabular}{|c|c|c|c|c|c|c|c|c|}
\hline \multirow[b]{2}{*}{ Answer options } & \multicolumn{8}{|c|}{ Years } \\
\hline & 2007 & 2008 & 2010 & 2013 & 2015 & 2016 & 2017 & 2018 \\
\hline Pride & 68,4 & 62,1 & 76,8 & 84,1 & 89,5 & 92,2 & 89,4 & 90,7 \\
\hline Satisfaction & 25,3 & 31,3 & 17,7 & 13,9 & 9,4 & 5,4 & 9,5 & 8,0 \\
\hline indifferent & 4,3 & 3,0 & 3,2 & 1,2 & 0,6 & 1,6 & 0,4 & 0,3 \\
\hline Difficult to answer & 3 & 3,6 & 2,3 & 0,8 & 0,5 & 0,8 & 0,7 & 1,0 \\
\hline
\end{tabular}

Table 2

Distribution of the respondents' answers to the question "How do you feel about being a citizen of Uzbekistan?"

\begin{tabular}{|c|c|c|c|c|c|c|c|c|}
\hline \multirow{3}{*}{ Regions } & \multicolumn{8}{|c|}{ Answer options } \\
\hline & \multicolumn{2}{|l|}{ Pride } & \multicolumn{2}{|c|}{ Satisfaction } & \multicolumn{2}{|c|}{ indifferent } & \multicolumn{2}{|c|}{ difficult to answer } \\
\hline & 2017 & 2018 & 2017 & 2018 & 2017 & 0,3 & 2017 & 2018 \\
\hline Total & 89,4 & 90,7 & 9,5 & 8,0 & 0,4 & 2,3 & 0,7 & 1,0 \\
\hline Tashkent city & 74,3 & 87,2 & 23,3 & 10,5 & 1,2 & - & 1,2 & - \\
\hline Republic of Karakalpakstan & 90,5 & 85,5 & 9,5 & 14,5 & - & - & - & - \\
\hline Andizhan & 83,0 & 90,1 & 15,0 & 9,9 & 1,0 & - & 1,0 & - \\
\hline
\end{tabular}

The attitude of Slavic nationalities to citizenship remains stable. According to the survey there are not people who are indifferent to their citizenship among Slavic. $61.5 \%$ of them said they felt proud to be citizens of Uzbekistan, and $30.8 \%$ said they felt satisfied.

Representatives of all age groups, regardless of age, feel proud and satisfied to be citizens of Uzbekistan. For several years of survey, among the age of $18-20$ (97.6\% in 2010, $100 \%$ in $2013,92.8 \%$ in $2015,93 \%$ in $2016,91.2 \%$ in 2017 , $89.1 \%$ in 2018$)$ and among the age of 24 years $(91.0 \%$ and $92.3 \%, 98.2 \%, 90.2 \%, 92.9 \%, 94.1 \%, 90.8 \%), 40-49$ years (92.1\% and $92 \%$, respectively) $\%, 97.3 \%, 92 \%, 90.7 \%$, $91.5 \%, 92.5 \%$ and $50-59$ years old $(99.4 \%, 98.1 \%, 89.3 \%$,
In the regional context, Sirdarya (100\%), Kashkadarya (99.0\%), Surkhandarya (98.8\%), and Bukhoro residents $(96.8 \%)$ feel more proud (Table 2 ).

From the point of view of belief, a person's understanding of citizenship towards a particular person is unique to Central Asian peoples (83.5\%). Slavic ethnic group \%) are less likely to perceive the community as a spiritual identity. (If the total number of responses exceeds $100 \%$, it means that the participants have more than one solidarity and solidarity of our multinational people, which is our main asset and which we are proud of, is a sacred duty of anyone who sees Uzbekistan as their motherland" [9, 298].

cording to a survey conducted by the Republican opic "Uzbekistan - our common home", "Emotional part of civil self-consciousness" the following cases were entified. homeland is outstanding indicator of civic solidarity in majority of respondents feel pride in being 2016). For many Uzbeks, that feeling remains the same.

$90.6 \%$, respectively). $\%, 89.2 \%, 87.0 \%$ ) these feelings remain stable. The importance and importance of this information is first and foremost that all generations have a strong sense of citizenship and patriotism.

Thus, the data obtained indicate a high level of citizenship and patriotism in Uzbekistan.

As a person knows his own identity and obtains deeper knowledge on his or her lineage, the feeling of love for his country grows.
The emotional level of citizens' feelings towards their 


\section{SOCIOLOGICAL ANALYSIS OF THE NATION'S IDENTITY, THE LEVELS OF FEELING THE NATIONAL IDENTITY IN UZBEKISTAN}

The deeper the root, the love for the country where it was born and raised will be greater. The truth of history shows that only those who are deeply rooted in national pride and love for the country will be able to do great things. We have to create such a spiritual environment that, in every corner of the country, in the face of all our cities and villages, the feeling of pride in the motherland will keep our eyes and hearts alive. [10, p.90].

\section{RESULTS \& DISCUSSIONS}

As we all know, patriotism is the moral basis of the life of every state and acts as the most important driving force in the comprehensive development of society .

The sociology of citizenship in Uzbekistan was determined by the questionnaire in question: "What is important to you - your nationality or your citizenship?" (Figure 1).

Monitoring of public opinion allows the Uzbeks to say that they believe that nationality and citizenship are important to them $-57.5 \%$ (59.4\% in 2017). An analysis of societal attitudes about the relation of "nationality" or "citizenship" allows us to trace a number of important trends related to the choice of the final one-sided options (nationality or only citizenship).

Sustainable growth in the number of respondents who believe that citizenship is more important than nationality (since 2003) changed in 2018. That is, in 2018, respondents noted that the nation is more important to them (25.0\%).

Figure 1. Distribution of respondents' answers to the question "What is important to you - your nationality or citizenship?"

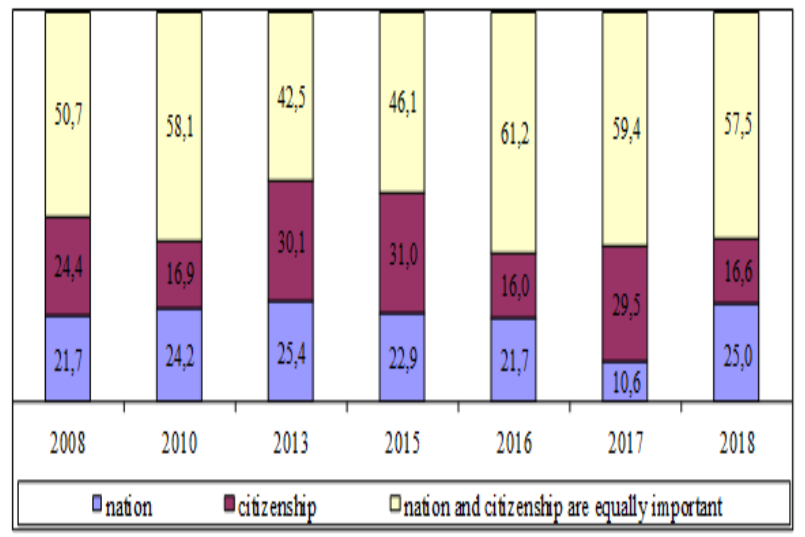

Citizenship and ethnicity are also important for the representatives of Tajik (82.8\%), Turkmen (80.0\%), and Uzbek $(57.9 \%)$ nationalities. Both Slavic and nationality $(46.2 \%)$ are equally important for Slavs.

In general, the results of the study revealed that in Uzbekistan, regardless of various social factors, there is a stable civil society, which is clearly reflected in the equality of both national and civil identity. At the same time, the 2018 study shows a change in this trend, which is reflected in the growing number of respondents who think national identity, is important to them.

Thus, in order to determine the identity of the person a clear belief that the identity of both national and civil identity is equally important for Uzbek people.

As to the wise man, there is no person without nationality. Every person in the world is from a certain nationality or ethnicity. Therefore, people who create any culture, any value, and all their material and spiritual wealth, are the highest values of their own nation. As Alisher Navoi states in his book "Vaqiya": "All things in the heavens and in the sky, all the seas and all that is in them, all the countries and all the good things in them - the best things are created for man, for his happiness, which must serve the whole of man."'[11, p.235]

\section{CONCLUSIONS}

In summary, the true socio-historical basis and sources of the national pride of each nation and the means of its formation and development vary widely across nations. In particular, the main source of the national pride of the Uzbek people is in many respects the cultural heritage and national spiritual values of the past. Therefore, the level and development of the national pride of our people depends on how much people learn and master the rich cultural heritage and high national spiritual values.

Simply the courage and strength of our people, irresistible will and determination, and most importantly, strong belief in independent development are the only guarantee of achieving our ambitious goals [12.p, 94].

Adoption and consistent implementation of the Strategy of Action on the five priority directions, the unique development document of Uzbekistan for 2017-2021 opened a new stage in its development.

President Shavkat Mirziyoyev spoke about the role and importance of this strategy in the life and society of our people and emphasized the following: "Our task is to strictly implement our own model of development and renewal, based on accumulated experience and best international practice. In this regard, we must act decisively in order to achieve main goals". [13.p, 124]

This means that our country is multinational and its history, national identity, language, customs, traditions, values and mentality of the nation are diverse and diverse. Our job is to preserve this identity and pass it on to the next generation. It is our main task to instill in the spirit of the younger generation an awareness of the independence of the nation - the commonality of national interests, needs and the need to achieve national development and strengthen its place in the world community.

Therefore, identity combines all national features and characteristics of national identity. It is a natural process for each individual to seek national identity. The ethnicity of the nation, the ethnicity of the nation, is a reflection of their efforts to preserve, develop, or restore the character.

\section{REFERENCES}

1. From national revival to national development "Youth Publishing House". Tashkent -2019. [1.p, 144], [5.B, 146], [1.p, 144], [5.p, 146]

2. Kurbanov T.H. The role of cultural heritage in the formation of national pride in young people. Philosophy Science. Candidate diss. NUU. Tashkent. 2005. p.139

3. Madaeva Sh. Anthropology of Identity. - Tashkent, 
Publishing House, 2015. p.154

4. Tulenov J. The philosophy of values. -Tashkent. Uzbekistan, 1998. [4.p, 61], [11.p, 235].

5. Idirov U., Tashkhodjaev S. Deepening internationalization globalization.-T: Journal of Society and Governance, 2007, No.2

6. Otamuratov S. Globalization and the nation. Tashkent., "New Generation Generation", 2008., p-137

7. Mirziyoev Sh.M. We will continue with determination and take to a new level. - Tashkent.: Uzbekistan, No. 1, 2017. [8.p, 298], [12.p, 94], [13.p, 124].

8. Ubaidullaeva R., Ota-Mirzaev. Uzbekistan in the mirror of public opinion. Tashkent: Iqtisod-Moliya, 2016.-P.98

9. Karimov I.A. High spirituality is an invincible force. Spirituality, Tashkent: -2010. p.-90. 